\title{
Effusion Volume Measurement
}

National Cancer Institute

\section{Source}

National Cancer Institute. Effusion Volume Measurement. NCI Thesaurus. Code C161424.

The amount of three dimensional space occupied by the effusion fluid. 